\title{
A Revolution that never happened
}

\author{
Ursula Klein \\ Max Planck Institute for the History of Science, Germany
}

\section{A R T I C L E I N F O}

\section{Article history:}

Available online 19 December 2014

\section{Keywords:}

Chemical revolution;

Ontology of substances;

Elements;

Mixts;

Chemical compounds;

Affinity

\begin{abstract}
A B S T R A C T
If we define scientific revolutions as changes of scientists' ontologies, types of causal explanation, and paradigmatic types of methods and instruments, Antoine-Laurent Lavoisier's contribution to chemistry did not amount to a scientific revolution. Contrary to the received view that Lavoisier initiated a "chemical revolution," which is accepted by Chang and Kusch, I argue that Lavoisier shared with the phlogistonists their "flat ontology" of chemical substance, established decades before the 1770s, their types of explaining chemical transformation, and their quantitative methods. Based on my historical reconstruction, I criticize Chang's argument that the late eighteenth-century phlogistic systems and Lavoisier's system belonged to two different theoretical traditions. As a consequence, I also question Chang's argument that the acceptance of Lavoisier's system can be explained in terms of dominance of "compositionism" over "principlism."
\end{abstract}

(c) 2014 Elsevier Ltd. All rights reserved.

When citing this paper, please use the full journal title Studies in History and Philosophy of Science

\section{Introduction}

As is well known, Thomas Kuhn highlighted Lavoisier's "chemical revolution" as a clear example of a large scientific revolution (Kuhn, 1962, pp. 6, 56, 92,118). This contribution to our symposium on the "chemical revolution" challenges the view that Lavoisier initiated a revolution of chemistry. I will study the following questions. Did Lavoisier (and his collaborators) introduce "deep" changes of chemistry that can be reasonably called a revolution? Did he change chemists' ontology of substances? Did he change their type of causal explanation of chemical transformations? And did he introduce novel methods and instruments? ${ }^{1}$ Instead of

\footnotetext{
E-mail address: Klein@mpiwg-berlin.mpg.de.

1 This essay elaborates arguments presented in Klein and Lefèvre (2007). For reasons of space, I do not discuss in any detail the fourth question concerning instruments and methods. It should be noted, however, that many phlogistonists performed exact quantitative experiments (see my remarks in part 2). I also omit many interesting questions concerning biographical details as well as institutional, social and technological contexts of eighteenth-century chemistry. Hence, it is also beyond the scope of this paper to discuss the question of whether Lavoisier's system led to a separation of chemistry from pharmacy and other artisanal practices; as Sacha Tomic has recently shown, much of the old connection between chemistry and pharmacy were preserved in nineteenth-century France (Tomic, 2010).
}

following the path to Lavoisier's system, I will compare the phlogistic and the antiphlogistic system from a broader historical and philosophical perspective. My approach invites restricting the meaning of "scientific revolution" to radical change that is analogous to social and political revolutions (Kuhn, 1962, pp. 92-94).

I will show in the following that an examination of the questions asked above yields an overall negative result. Lavoisier's work affected less fundamental levels than chemists' ontology, ways of causal explanation, and paradigmatic empirical methods. Moreover, they were not changes of chemistry, but rather changes within the chemical discipline that left many chemical subjects untouched. As F. L. Holmes pointed out many years ago, Lavoisier's system did not extend to all fields of chemistry. ${ }^{2}$

Based on my conclusion that there was no chemical revolution, the question of acceptance of Lavoisier's system appears in a new light. As the phlogistic and anti-phlogistic systems were not incommensurable, but rather shared significant conceptual features, paradigmatic classes of substances, and methods, chemists

\footnotetext{
2 Holmes (1989), p. 107. Lavoisier made no systematic contribution to the flourishing chemical sub-field studying proximate organic components. Nor did he extend his system to useful materials and minerals such as ores and stones, which were at the center of mineralogical chemistry; see also Klein and Lefèvre (2007).
} 
could easily shift from one system to the other. It is out of the scope of this essay to study comprehensively the reasons why chemists accepted Lavoisier's system in the course of some twenty years after the publication of Lavoisier's Traité élémentaire de chimie (1789). Apart from reasons discussed by Chang and Kusch, I propose additional ones, which relate to late eighteenth-century chemists' shared goals and communal interests. I argue that Lavoisier's system facilitated both chemical teaching and communication and that this fact played an important role for its acceptance.

\section{Chemists' ontology of substances}

The question of what kinds of substances were included in Lavoisier's theoretical program, and what kinds of substances were excluded, has been rarely asked in the existing histories of the "chemical revolution." 3 In Lavoisier's theories several substances-phlogiston, oxygen, caloric, water, acids, and permanent gases-played a paradigmatic role. However, the range of substances he studied from a theoretical perspective was also clearly restricted. The eighteenth-century chemists studied a much broader variety of substances than Lavoisier did in the context of his selfpronounced chemical revolution. They analyzed minerals as well as animal fats, vegetable oils, gums, resins and many other "proximate principles" of plants and animals. In addition, chemists examined a plethora of useful materials that were of highly complex nature. Indeed, Lavoisier, too, studied materials such as porcelain and coal, which were not on his theoretical agenda. Why did Lavoisier exclude ores, stones and other raw minerals as well as plant and animal substances from his system? Inversely, what were his criteria for focussing on substances such as gases, metals, acids, and salts? What were eighteenth-century chemists' beliefs about the kinds of substances that existed in the world? What causes did they invoke to explain the existence of the enormously broad variety of substances? And how did they connect their ontology of substances with their causal explanation of chemical transformations?

\subsection{The pre-modern hierarchical ontology of substances}

Let us start with a brief discussion of the pre-modern ontology of substances, which differed in important aspects from the views of both the late phlogistonists and Lavoisier and his group. For centuries chemists had assumed that the substances belonging to the mineral, animal and plant kingdom were composed of different simple "elements" (or "principles") and that the qualities of the elements, and their interactions, caused the properties of the broad variety of different kinds of natural substances. However, chemists' attitude towards "elements" and their understanding of the substances they handled in their laboratories underwent considerable change over time.

The vast majority of pre-modern chemists (or alchemists) conceived of elements as causes that engendered the different kinds of substances existing in the natural world. In sharp contrast to the large number of ordinary natural substances, the number of elements was small, ranging from one to five. ${ }^{4}$ All naturally occurring species of substances belonging to the mineral, vegetable and animal kingdom were defined as "mixts," without any exception. The term "mixts" expressed the belief that the different kinds

\footnotetext{
${ }^{3}$ In Klein and Lefèvre (2007) we have focussed on this question.

4 The following is a rough outline of pre-modern chemical ontology, which omits differences such as the one between Aristotelian four elements, Paracelsian elements and principles, the Paracelsian distinction between active and passive principles, and J. B. Van Helmont's elemental water. For more detail see Klein (1994)
}

of mineral, plant and animal substances were "generated" from elements and that the qualities of the latter mixed in the process of generation. In the context of this pre-modern chemical ontology, elements were not ordinary natural substances but rather causes, few in number, that brought the variety of mixts into existence and determined their specificity. ${ }^{5}$

Pre-modern chemists' distinction between different ontological levels of material "substances"-the causal elements and the variety of natural mixts - was an Aristotelian heritage. The distinction implied an ontological hierarchy according to which the simple elemental causes were more important than the multiplicity of natural mixts generated by them. The Aristotelian heritage was also alive in the most influential version of pre-modern alchemy, Paracelsianism, which re-interpreted Aristotelian concepts from a hylozoistic perspective.

In the intellectual framework of the Aristotelian (and Paracelsian) tradition all mixts were further defined as homogeneous substances, the same in all their parts. Homogeneity of mixts emerged in the process of "generation," in which the qualities of the constituting elements interacted and converged into a uniformly balanced whole, whose "form" or specificity depended on the proportions of the elements. The meaning of "generation" was also determined by its Aristotelian context. "Generation" of mixts from elements was a slow, natural process, which differed in many aspects from chemical transformations performed in the laboratory. Unlike the early modern chemical concepts of analysis and synthesis, the concept of generation was not embedded in, and not derived from, experimentation in the laboratory.

This very rough outline of the pre-modern philosophy of elements and mixts omits many interesting aspects, such as critical questions addressed to it from the late middle ages and the early modern atomists' and corpuscular philosophers' attempt to answer these questions. In the course of the seventeenth century, the concepts of mixts and elements became a target of fierce critique by corpuscular philosophers like Robert Boyle (1627-1691). Chemists had long tried to separate the elements from the mixts by chemical art. As a result of their failure, many late seventeenth-century chemists' grew sceptical that chemical art was able to achieve this goal. Perhaps the elements were so intricately mixed that even the strongest fire was unable separate them from each other. Thus it is not accidental that Boyle choose the title The Sceptical Chymist (1661) for one of his most prominent chemical publications. As I will show in the next part, other fields of chemical art were crowned with more success.

\subsection{The early modern 'flat ontology' of chemical substances}

In the course of the seventeenth century, chemists, chemical physicians and apothecaries produced an increasing number of salts from acids and certain "bases"-metals, alkalis and earths-and again decomposed these salts into their original ingredients, mostly by way of displacement reactions adding a third substance. Likewise, early modern chemists, goldsmiths, masters of the mint and other metallurgists were able to mix different kinds of metals to produce brass, bronze and other alloys and further to recover the original metals from the alloys. Performing these kinds of "reversible" compositions and decompositions, they had also observed that substances could not be transformed at will and that there were rather preferences or "affinities" between pairs of certain substances that were absent in other cases and seemed to direct chemical interaction.

\footnotetext{
5 They were material and formal causes in the Aristotelian sense.
} 
For an appropriate historical understanding of eighteenthcentury chemistry it is important to have a close look at the specific kinds of substances that actually allowed performing these

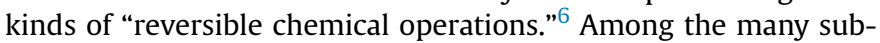
stances studied by early modern chemists, it was a very distinct group of substances-mainly metals, acids, alkalis, "earths," alloys and salts-that displayed this distinct kind of chemical behaviour. We may designate them "chemical substances" in a narrower sense. It was exclusively the study of this particular group of "chemical substances," along with studies of the reversible operations carried out with them, that resulted in a new sub-field of eighteenth-century chemistry with a particular conceptual structure. As I will show in the next paragraphs, this distinct chemical sub-field was independent of the older ontology of elements and mixts, and it became the platform for Lavoisier's work. ${ }^{7}$

"Chemical substances" in the narrower sense such as metals, acids, and alkalis were sufficiently stable to be used as ingredients to prepare more compounded substances (such as salts and alloys) and to be recovered from these chemically synthesized compounds in subsequent chemical analyses, in the direct way or through displacement reactions. Almost all of these chemical substances came from the arts and crafts, in Europe or overseas, or were products of the laboratory. They were not natural substances in a common sense, but proceeded products of natural raw materials. Compared to the vast majority of minerals, plants and animal substances left in their natural state, they were relatively "pure" substances in a modern chemical sense. Thus it is not accidental that the modern chemical concept of purity emerged exactly in the context of reversible operations performed with these kinds of chemical substances, as did the modern chemical concepts of analysis and synthesis (Klein, 2012, 2013). Furthermore, almost all of the reversible chemical operations presented in Geoffroy's table in an abstract way were also performed in the pharmaceutical and metallurgical arts (Klein, 1994).

Based on accumulated experience with reversible chemical operations, the French chemist and apothecary Etienne François Geoffroy (1672-1731) constructed a chemical table in 1718, which marks a peak in a long chemical evolution (Duncan, 1996; Kim, 2003; Klein, 1995; Klein \& Lefèvre, 2007). Geoffroy's table did not refer to the same type of explanandum as the Aristotelian concepts of elements and mixts. The latter provided an explanation for the existence of a broad variety of natural substances and their different properties. And they did so in the context of a hierarchical ontology and a long natural philosophical tradition, going back to the pre-Socratics, who regarded the multiplicity of things as a vexing problem. By contrast, Geoffroy's table referred to chemical

\footnotetext{
${ }^{6}$ The term reversible chemical operations has been introduced in Klein (1994). "Reversible" refers to operations of decomposing and re-composing chemical substances; it must not be understood in today's chemical sense. The particular kinds of chemical substances that lent themselves to such reversible operations, have also been studied in Klein and Lefèvre (2007). As a shorthand, we have designated these substances "pure substances". Alan Chalmers has rightly pointed out that our talk of "pure substances" might be misleading (Chalmers, 2012a).

7 My argument differs from Siegfried's (and Dobbs's), which has been the starting point for Chang's work on eighteenth-century chemistry; see Chang (2012), p. 37; Siegfried and Dobbs (1968); Siegfried (1982), (1988), (2002). Siegfried has argued that eighteenth-century chemists slowly transformed the existing "metaphysical" concept of elements into a modern, "operational" one. He tells a linear "story of the movement of chemical theory from metaphysical ELEMENTS to operationallyfunctional ATOMS" (Siegfried, 2002, p. V). Focussing on the change of the meaning of "element" and "composition," he conflates the pre-modern concept of "mixt" with the early modern concept of "chemical compound." By contrast, I argue that the early modern concept of chemical compound differed from "mixts" and first developed independent of the Aristotelian and Paracelsian concepts of elements and mixts, namely in the distinct context of studies of reversible chemical operations and of more proximate components of chemical compounds.
}

operations performed in the laboratory, and the multiplicity of substances was not a problem here.

The form of a table was a novelty of its own. ${ }^{8}$ Symbolic and tabular representation enabled Geoffroy to dispense with traditional philosophical questions. It allowed him to outline the field of paradigmatic substances undergoing reversible decompositions and re-compositions-restricted to displacement reactions-and to represent the rapports among pairs of such substances, independent of any further causal explanation of displacement reactions and of the internal constitution of the substances that underwent such reactions. The symbols included in Geoffroy's table meant ordinary substances, and all substances had the same ontological status. They were stable building blocks involved in displacement reactions and forming new chemical compounds, regardless their own internal constitution. For example, the table presented metals, considered to be relatively compounded substances, in exactly the same way as acids, considered to be relatively simple substances. Hence metals entering alloys as components were defined as "proximate components" (or "proximate principles"). In this way Geoffroy rendered the concepts of chemical compound and of chemical composition independent of the philosophical concept of simple element. ${ }^{9}$ Geoffroy's table rather black-boxed all philosophical questions concerning simple elements.

Geoffroy's table of chemical rapports or "affinities" defined the salts, alloys and solutions, which resulted from displacement reactions, as "chemical compounds" in an early modern sense. A "chemical compound" in the early modern sense was a substance whose components stemmed from the ingredients used to prepare it. Chemists assumed that the ingredients were preserved in the making of a compound, just like stable building blocks. As a result, a chemical compound was not the same in all its parts, but consisted of different substance components. This was another important difference from the concept of homogeneous mixts in the Aristotelian tradition, in addition to the concept of proximate component. Although Geoffroy did not use the term "proximate components" (see below), this facet of meaning was clearly implied in his concept of chemical compounds. ${ }^{10}$ Unlike a mechanical mixture, however, a "chemical compound" was conceived to be a distinct species of substance, whose building blocks were selectively tied together by chemical affinity.

The early modern concept of chemical compound was part of a more comprehensive conceptual system that comprised also the concept of affinity along with the assumption of different degrees of affinity between pairs of substances as well as the concepts of composition, component, chemical analysis, synthesis, simultaneous analysis and synthesis (displacement reactions), and even chemical "reaction" and "purity." In the following I call this system of concepts "conceptual system of chemical compounds and affinity."

The ontology of substances involved in the latter system differed sharply from the Aristotelian concepts of elements and mixts. The components of a chemical compound had the very same ontological status as the ingredients of the compound made from them. They were no longer Artistotelian causes but rather ordinary laboratory substances or proximate components. Most of these "chemical substances" were even known from the arts and crafts.

\footnotetext{
8 The construction principles of this table are described in detail in Klein (1995); the table is reproduced in Klein and Lefèvre (2007), p. 149; an English translation of Geoffroy's own comment to the table is contained in Science in Context 9 (3), 1996, pp. 313-320.

9 See note 7 concerning Siegfried's interconnection of "chemical compound" with simple "element."

10 For a discussion of reasoning with proximate causes in the Scientific Revolution see Chalmers (2012b).
} 
Compared to the Aristotelian ontological hierarchy, the modern ontology of chemical substances may be designated a "flat ontology."

Given the fact that the early modern concept of chemical compound emerged in studies of reversible chemical operations-first performed in chemical arts and then presented in abstraction from the latter in Geoffroy's affinity table-there was no compelling logic to regard this concept as a direct challenge of, or alternative to, the older natural philosophy of elements, natural mixts, and natural generation. Whereas the latter studied nature, focussing on elements conceived as causes of the multiplicity of natural kinds of substances ("mixts"), the former referred to a distinct group of ordinary substances and their transformations in the laboratory. ${ }^{11}$

\subsection{Chemists' agnosticism}

Whereas seventeenth-century corpuscular philosophers like Robert Boyle used knowledge about reversible decompositions and re-compositions for elaborating philosophical alternatives to the Peripatetic ontology of mixts and elements, the general trend in eighteenth-century chemistry went in a different direction. ${ }^{12}$ Scepticism concerning reliable empirical knowledge about simple elements often gave way to agnosticism. Well into the late eighteenth century chemists discussed philosophies of elements and mixts in their teaching and textbooks. Yet, in their experimental research, they turned to different objects of inquiry that were more promising.

Georg Ernst Stahl (1659-1734) belonged to the early eighteenth-century chemists who explicitly articulated chemists' scepticism. He distinguished between compounded substances and simple "principles," which were "the first material causes of Mixts," and he further divided compounded substances into "mixts," "compounds," and "aggregates" (Stahl, 1730, p. 3). According to Stahl, only "mixts" were immediately composed of simple principles. By contrast, "compounds" were composed of mixts, and "aggregates" were composed of compounds. After a discussion of existing views about simple principles (or "elements") and mixts, Stahl concluded that due to the "firmness" of mixts many chemists rightly believed that it was "an impossibility" to decompose them into their principles. Yet "compounds," he stated, "as they are easily dissolved, so they are easily united by Art" (Stahl, 1730, p. 11). ${ }^{13}$ Stahl's definition of compounds and aggregates nicely exemplifies my interpretation of the early modern meaning of the concept of chemical compound, implied in Geoffroy's affinity table. According to Stahl, the components of "compounds" (and of "aggregates") had the same ontological status as the "compounds"; they were "mixts," or proximate components, of the "compounds." Like Geoffroy's table, Stahl rendered his reasoning about composition independent of considerations about the internal constitution of mixts and the concept of simple elements (see note 7). His concepts further highlight the importance of reversible chemical operations for studying chemical compounds and composition.

Around the mid-eighteenth century the vast majority of chemists was convinced that all substances they experimented

\footnotetext{
11 Early eighteenth-century chemists did not regard art and nature as opposites, but they did not conflate them. There were still many unsettled questions concerning the relationship between nature and chemical art in eighteenth-century chemistry.

12 Boyle re-defined elements as corpuscles possessing distinct textures; texture determined the species of homogeneous mixts.

13 Earlier in the text, he stated that a "pure, natural resolution" of substances into ultimate principles was "not easily obtainable from the Chemistry of these days" (Stahl, 1730, p. 4).
}

with were of compounded nature. Some of them were simpler and could not be further decomposed by the available analytical means, whereas others were of more compounded nature and could be further decomposed into their proximate components. This trend can be well observed in plant chemistry. From ca. 1690s until 1710, chemists of the Paris Academy of Sciences had undertaken herculean efforts to separate the simple elements from hundreds of different plants (Holmes, 1989; Stroup, 1990). A few decades later, however, this kind of analytical program was disbanded. Instead, chemists tried to separate the proximate components, or "proximate principles," from plants (Klein \& Lefèvre, 2007; Löw, 1977). Chemists then argued that not the most simple elements of plants but rather their more proximate principles (such as resin, gums, oils, and salts) caused their sweet or sour taste, aromatic smell, medical virtues and so on. Proximate principles were clearly simpler than the organs, tissues and products of plants they were extracted from, but they could be further decomposed by chemical means. They were ordinary laboratory substances, and most of them were used in medicine and commerce.

The events can be best described as a silent move away from the old hierarchical ontology of mixts and simple elements and towards an integration of plant chemistry into the flat ontology of the conceptual system of chemical compounds and affinity, which had originally been constructed in a different subfield of chemistry. Plant chemistry illuminates a more general trend in eighteenthcentury chemistry, and I am tempted to propose a social explanation for this trend. The old explanandum of Artistotelian natural philosophy, to which the concepts of simple elements and mixts provided an answer-namely, the fact that there was a broad variety of different substances in the world rather than a few, unchangeable kinds of matter-was no longer a vexing problem in the early modern period, in particular not for chemists. On the contrary, as chemistry was closely linked with various arts and crafts, the multiplicity of continuously changing things was an unquestioned part of their social and cultural milieu. Instead of demonstrating that there was another world of ultimate and eternal causes, which was more important than the everyday world, early modern chemists were more interested in particulars, many of which were worldly goods, and in possibilities of their chemical transformation. We may also describe the trend as a move away from natural philosophy and towards a modern, more "technical" science that was closely related to industry and technology (on the technicality of modern science see also Porter, 2009).

In the 1770s, when Lavoisier began to re-consider theoretical questions concerning the composition of substances, the old theory of elements and natural mixts was still transmitted in teaching but played no longer a role in chemical research. The German chemist Martin Heinrich Klaproth (1743-1817), for example, who was a radical empiricist focussing on mineral analysis, found himself compelled to mention in his chemical lectures the "simple elements of nature," out of which the "Creator, through endless modifications, formed all of the other natural bodies." Yet he added that knowledge about the simple elements "transcended experience" (Klaproth, 1789, p. 3). Hence, apart from an introductory lecture, the bulk of his course was concerned with empirical chemical substances.

By contrast, Lavoisier apparently regarded the discrepancies between chemical teaching and chemical research as a theoretical challenge. His introduction of the concept of "simple substances" (see below) can be seen as an answer to this challenge. Lavoisier's most important contribution to chemistry was his reintroduction of theory into the European community of chemists, which had long been guided by theoretical agnosticism and empiricism. 


\subsection{Phlogiston-against "principlism"}

In his recent book, Is Water $\mathrm{H}_{2} \mathrm{O}$ ?, Hasok Chang scrutinized the achievements of the late eighteenth-century adherents of the phlogiston theory (Chang, 2012). Much in line with the methodology of the sociology of scientific knowledge, Chang takes a symmetrical approach to the phlogistic and anti-phlogistic theories (Bloor, 1976). His symmetrical approach is very welcome, as it yields new insights into a complex field that is still discussed controversially among historians of chemistry.

As Alan Chalmers has pointed out, however, Chang does not go far enough in his critique of the received view of the "chemical revolution" (Chalmers, 2013). His acceptance of the argument that Lavoisier initiated a "chemical revolution" relies significantly on his distinction between two theoretical traditions that he calls "principlism" and "compositionism." "The phlogistonist system was a particular instantiation of principlism," Chang states, and Lavoisier's "oxygenist system was a particular instantiation of compositionism" (Chang, 2012, p. 38). He further argues that "Each system incorporated a significant metaphysical doctrine about the fundamental ontology of substances, which differed from each other sharply" (Chang, 2012, p. 37). In the next two parts I criticize this interpretation, presenting an alternative one. I first focus on phlogiston, which, according to Chang, was a paradigmatic ontological entity of "principlism."

At first glance, the hypothetical character of phlogiston and its explanatory function for certain properties of substances such as combustibility and colour speak for an ontological status that differed sharply from that of ordinary substances and instead shared features with the Aristotelian elements and Paracelsian principles. Compared to metals, acids, salts and so on, included in Geoffroy's table, which were for the most part substances known in the arts and crafts, "phlogiston" was an object of inquiry constituted in a theoretical context. Moreover, the concept of phlogiston originated in the chemical philosophy of elements and mixts by Johann Joachim Becher (1653-1682). Stahl, who introduced "phlogiston," explicitly referred to Becher's chemical philosophy, which postulated that "water" and "earth" were the "immediate principles" of all mixts, and further that there were three different kinds of earth, the vitrifiable or fusible earth, the liquefiable or mercurial earth, and the inflammable earth. Stahl derived his "phlogiston" from the latter (Stahl, 1730, p. 8).

But Stahl's concept of phlogiston also differed from Becher's inflammable earth in important aspects. According to Stahl's theory, combustible substances like charcoal and sulphur were decomposed through combustion into phlogiston and ashes, or an acid, respectively. The theory also explained the transformation of base metals into "metal calces" (later oxides). Stahl stated that metals were separated into particular metal calces and phlogiston through "calcination"; he further argued that this process could be reversed through the "reduction" of metal calces into metals by means of charcoal, which contained a large proportion of phlogiston. Thus phlogiston was involved in reversible operations, and it was a simpler substance than metals and combustibles. However, this does not imply that it was a simple principle or element. In his theory of composition, Stahl clearly defined base metals to be "compounds" rather than "mixts." ${ }^{14}$ We can conclude from this definition, that he regarded their two components-metal calx and phlogiston-to be mixts. In other words, Stahl attributed to phlogiston the same ontological status as to metal calx, which was a well known laboratory substance also defined as a "mixt."

\footnotetext{
14 Stahl (1730), p. 15: "The other Metals [other than gold and silver] are not Mixts
} but Compounds."
As early as 1718 , Geoffroy included phlogiston in his affinity table. Based on an experiment that he and others interpreted to be a re-composition of ordinary sulphur, he argued that phlogiston (which he designated principe huileux and soufre principe) had a stronger affinity with sulphuric acid than alkalis, earths, and metals. ${ }^{15}$ Ordering phlogiston into his affinity table, Geoffroy ascribed affinity to it. In so doing, he integrated it into the same experimental context of reversible chemical operations that I have identified above as the empirical scaffolding of the early modern conceptual system of chemical compounds and affinity. Again, this proves that phlogiston had the same ontological status as ordinary laboratory substances.

From the mid eighteenth century onward several chemists elaborated on this approach. The French chemist Jean Philippe de Limbourg (1726-1811) argued that phlogiston had a strong affinity with all kinds of acids; in his enlarged affinity table (1758) he listed its affinities in a column for acids in general (Kim, 2003, p. 227). The Swedish chemist Torbern Bergman (1735-1784) also included metal calces in his table of affinities (Bergman, 1785). He emphasized that acids formed salts with metal calces, not with metals, and he explained the formation of these kinds of salts as displacement reactions involving phlogiston. ${ }^{16}$ Moreover, Bergman performed quantitative analyses of metals to determine their relative content of phlogiston. ${ }^{17}$ Hence, Geoffroy, Limbourg and Bergman involved phlogiston in explanations of reversible chemical operations, which Chang identifies as "compositionism" rather than "principlism."

The shared ontological and conceptual background of the phlogistic and anti-phlogistic theories becomes even more manifest when we turn to the late phlogistonists, who accepted a part of Lavoisier's theory of oxidation. Late phlogistonists' conceded that oxygen played a role in combustion and calcination, and Priestley and Klaproth even agreed with Lavoisier that oxygen caused the increase of weight of the combustible. But they also argued that phlogiston was simultaneously released from the latter. In so doing, they reasoned with chemical composition and affinities in the same way as Lavoisier did.

\subsection{Studies of properties}

I now discuss Chang's claims concerning "principlism" from another angle. Chang argues that "classifying substances according to observable properties" and "explaining the properties of substances by reference to principles" were characteristic epistemic activities in "principlism" (Chang, 2012, p. 38). By contrast, I will show that observation of properties was an indispensable part of chemists' way of identifying substances, which was shared by Lavoisier.

In my account of the meaning of the early modern concept of chemical compound (see above), I have embedded this concept in the context of reversible chemical operations that were mapped by affinity tables. In so doing, I have deliberately ignored a distinct feature of the early modern concept of chemical compound, and of

\footnotetext{
15 See the fourth column in Geoffroy's table, reproduced in Klein and Lefèvre (2007), p. 149. Accordingly, the symbol for the oily principle was placed directly beneath the symbol for sulphuric acid; for further explanation, see Klein (1995), pp. 85-86.

${ }^{16}$ In the first half of the eighteenth century, calcination of metals was understood as a simple separation of metals into a metal calx and phlogiston; likewise Lavoisier interpreted the reduction of the red mercury oxide as a simple separation into mercury and oxygen. The more ordinary case of analysis was displacement reaction, which separated two components of a compound by means of a third one, which led to the simultaneous formation of a new compound. As calcination was first not conceived to be a displacement reaction, Geoffroy did not include metal calces in his table. Bergman (1785); Klein and Lefèvre (2007), p. 167.

17 Kopp (1966), vol. 3, pp. 143-144; Partington (1961-1970) vol. 3, p. 191.
} 
chemists' related practices, that were not covered by affinity tables. This was their systematic study of observable and measurable properties and their assumption that the properties of compounds were determined by their components.

We have seen that in the context of affinity tables chemists identified chemical compounds from the perspective of their chemical behaviour. Acids, for example, were defined as substances that reacted with bases forming salts; a particular kind of acid was characterized through its degrees of affinity with particular kinds of bases; and a salt was defined as a compound consisting of an acid A and a base $B$. In this way, salts and other chemical compounds could be identified as distinct kinds or species of compounds and further classified on the basis of knowledge about their composition. However, this is only a part of the story. Had the chemists relied exclusively on knowledge about composition, their practice of identifying substances would have soon come to a dead end.

Radical "compositionism" does not work in practice. If a distinct species of salt $(A B)$, for example, were identified just as a substance consisting of the components $\mathrm{A}$ and $\mathrm{B}$, and the components $\mathrm{A}$ and $\mathrm{B}$ were identified as substances that interact chemically to form the species $(A B)$, the practice of identifying would have been a full circle. But this is not what chemists actually did. They identified compounds through knowledge of their composition, based on analysis and other studies of reactions, but they did so in addition to studies of properties. In order to clearly identify a species of substance, they also described its colour, smell, taste, specific weight and other measurable "physical properties." Lavoisier kept this complementary approach to the identification of substances, as did the chemists who came after him. It was only the classification of chemical compounds, not their identification, that could be based on knowledge of composition alone. Furthermore, in the case of Lavoisier's "simple substances" (see below) it was excluded to identify and classify them based on knowledge of composition; here, descriptions of observable properties had to suffice.

There was an interesting conceptual link between the two complementary methods of identifying substances, which might be easily conflated with Chang's "principlism." All eighteenth-century chemists, including Lavoisier and his collaborators, believed that the properties of chemical compounds were caused by their chemical components. For example, Lavoisier assumed that the component oxygen caused the taste of acids. The same idea is also manifest in chemists' concepts of "neutralization" and "middle salts." Both the phlogistonists and the adherents of Lavoisier's system assumed that acids and bases mutually neutralized their characteristic smell and taste in the making of middle salts. Was this way of explaining the properties of chemical compounds ultimately derived from the Aristotelian (or Paracelsian) philosophy of mixts and elements (or principles)? Clearly, the latter postulated that the properties of mixts were caused by the qualities of the elements they were generated from. Yet what we encounter here is a superficial similarity in meaning. It does not provide evidence for a living tradition of "principlism." As we have seen above, the meaning of the Aristotelian concepts of elements and mixt differed sharply from the early modern meaning of chemical component and compound; the former was embedded in a hierarchical ontology whereas the flat ontology of the latter implied that both the components and the compounds were ordinary chemical substances that possessed "properties." The component phlogiston was neither a simple principle nor a Aristotelian causa materialis and causa formalis. It was defined as a natural mixt, invested with affinity, which was an efficient cause. Moreover, it would be no less plausible to argue that chemists' explanations of the properties of compounds with reference to properties of their components stemmed from common sense considerations; it was common knowledge that the taste and smell of a cake, for example, depended on its ingredients and that the stability of a building depended on the kinds of materials it was construct from.

There was one particular aspect of chemical language that seems to speak in favour of Chang's "principlism." Phlogistonists stated that "combustibility" of substances was caused by phlogiston. What did this mean? Talk about "combustibility," "acidity" and so on implied a distinct approach towards substances' chemical activity. Instead of studying it as an interaction between different substances, and thus as a relational issue, chemical activity was here transformed into inherent properties of substances. Chemists designated these kinds of properties "chemical properties." ${ }^{18}$ It should be noted, however, that both the phlogistonists and the anti-phlogistonists reasoned with inherent chemical properties of substances, and they did so quite independent of the fact that they also explained chemical activity as reactions involving affinities. The term "chemical properties" is even used in modern chemical textbooks.

To sum the last two sections up, I argue that in the mideighteenth century, as the very latest, phlogiston was part of chemists' flat ontology of chemical substances, implied in their conceptual system of compounds and affinity, which Chang designates "compositionism." In other words, it was not a paradigmatic entity of "principlism." In connection with my study of Lavoisier's ontology of substances below, I will present further arguments against Chang's claim that there was a tradition of "principlism" in late eighteenth-century chemistry.

\subsection{Matter of fire and permanent gases}

"Matter of fire" or "heat" was another hypothetical substance of eighteenth-century chemists. In the late seventeenth century experiments on the calcination of metals with the burning glass had shown that an augmentation of weight took place during calcination. Chemists like Nicolas Lemery (1645-1715) explained this fact with the incorporation of the matter of fire (Kim, 2003, p. 116). In early modern studies of phenomena of heat, matter of fire was also the substance that caused increase of temperature and expansion of substances as well as the transformation of solid bodies into liquids and of liquids into vapours. Through the work of Joseph Black in the early 1750s, the matter of fire further converged with ordinary substances. Apparently it could be fixed by substances and transformed into "latent heat." There was also an analogy between the "capacity" of different substances to bind the matter of heat and the capacities of acids to bind bases and become "saturated" with it.

It was an open question, discussed controversially among the phlogistonists, how the matter of fire related to phlogiston. The French chemist Pierre Joseph Macquer (1718-1784), for example, conceived of phlogiston to be "elemental fire, which is combined with, and a principle of, combustible bodies" (Macquer, 1766, vol. 2, p. 202). By contrast, Klaproth demarcated the matter of fire (Feuerwesen, Wärmestoff) from phlogiston, arguing that the former could penetrate vessels whereas the latter was unable to do this (Klaproth, 1789, p. 8). When Lavoisier re-defined the older concept of matter of fire, re-naming it caloric, he profited from such kinds of discrepancies in the phlogistonists' camp. Notwithstanding the new name, caloric also shared many characteristics with phlogiston (see below).

Beginning in the mid eighteenth century, a novel class of substances entered chemistry: the different kinds of air or permanent gases. It took some time until chemists, all of them phlogistonists at

\footnotetext{
18 In the history of philosophy the metaphysical problem arising when one transforms a relation between two entities into an inherent property of just one
} entity was often criticized, most notably by Hegel. 
the time, believed that the different kinds of air were not just varieties or impurities of the ordinary atmospheric air but different kinds or species of air, later designated permanent gases. It is beyond the scope of this paper to discuss the historical events and changes connected with the recognition that there were truly different kinds of air in the world (Crosland, 2000). But it should be noted that this was an ontological move, which challenged the phlogistonists. They had to seek ways for integrating these new kinds of substances into their order of substances and theories.

The permanent gases possessed weight, they could be collected in pneumatic vessels, and they were used as ingredients for preparing new compounds (Levere, 2000). Studies of permanent gases thus extended the flat ontology of substances constructed around the conceptual system of compounds and affinity. Based on their earlier assumption that ordinary air always contained some phlogiston, stemming from combustions, calcinations and respiration, phlogistonists hypothesized that the different airs were distinct compounds containing specific proportions of phlogiston or being deprived of it (Boantza, 2013). Richard Kirwan (1733-1812) and Joseph Priestley (1733-1804), for example, identified the inflammable air (hydrogen) with phlogiston; by contrast, Klaproth believed that inflammable air was a compound consisting of matter of fire and phlogiston (Klaproth, 1789, p. 9). Phlogistonists thus ascribed new explanatory functions to phlogiston, which sometimes promoted new problems. In this situation, the phlogstonists did not work collectively on the emerging problems-as Lavoisier did-but tried to find individual solutions of problems. As a result, almost each phlogistonist studying permanent gases had his own theory concerning their identity and the role played by phlogiston.

Studies of matter of fire, or caloric in Lavoisier's terminology, phlogiston, and kinds of air spurred a broad variety of classifications and theories in the camp of the phlogistonists (Boantza, 2013, pp. 171-206). On the communal level, the phlogistonists fell apart. By contrast, Lavoisier systematically organized collaborations with experts to solve the existing puzzles. In 1787, he was able to present compelling results of collaborative efforts, which fulfilled a shared goal of chemists: a new chemical nomenclature, based on a reorganized chemical taxonomy.

\section{Lavoisiers' ontology of substances}

Based on what has been said above, I will now discuss the question of whether Lavoisier changed chemists' ontology of substances. I begin with remarks on Lavoisier's theory of permanent gases along with his concept of caloric and then turn to the bulk of chemical substances.

Lavoisier's studies of permanent gases heavily relied on the studies of Black, Priestley, Cavendish and other chemists, all of whom were phlogistonists. Lavoisier refined the existing methods of pneumatic chemistry and further elaborated a new theory of permanent gases. According to his theory, all permanent gases were binary chemical compounds of caloric with an unknown simple base or "radical." For example, what we call "oxygen" today was a compound of caloric in Lavoisier's system, which he designated "gas of oxygen;" and Lavoisier's "oxygen" was the simple hypothetical radical contained in the "gas of oxygen." In the same way Lavoisier also re-defined the inflammable gas, which many phlogistonists identified with phlogiston, as a compound consisting of caloric and a hitherto unknown component of water (and of organic substances) designated "hydrogen."

Lavoisier's theory that all permanent gases were chemical compounds consisting of caloric and a distinct hypothetical radical was closely linked with his new theories of combustion, respiration and fermentation. It relied on a comprehensive conceptual restructuring of these objects of inquiry. However, Lavoisier neither brought these objects of inquiry into existence nor introduced a new type of causal explanation for the formation of permanent gases. His theory of compounds of caloric reasoned with the existing concept of affinity and the building-block model of chemical compounds and reactions that had long been implied in the affinity tables.

\subsection{Lavoisier's caloric-remarks about methods}

It is well known that Lavoisier's theory of combustion and calcination abolished phlogiston. Less known is that Lavoisier's concept of "caloric" shared some important meaning with the older concept of matter of fire or heat (Lewowicz, 2011). Lavoisier argued that in combustion, or calcination, the oxygen contained in the oxygen gas combined with the combustible, while the second component of oxygen gas-caloric-was released. Free caloric then caused the increase of temperature as well as flames, which could be observed in the process of combustion.

While the late phlogistonists had accepted Lavoisier's proposition that oxygen was involved in combustion, or calcination, they maintained the view that phlogiston was simultaneously released from the combustible. According to their understanding, increase of temperature and flames were caused by the release of phlogiston from the combustible. ${ }^{19}$ Thus, the meaning of "phlogiston" and "caloric" partially overlapped. Both phlogiston and caloric were defined as invisible causes of increase of temperature and flames and further as imponderable substances displaying affinities with other substances. Lavoisier simply shifted explanatory functions away from phlogiston and towards caloric. In other words, in his theory of combustion the main substitute for phlogiston was not oxygen but rather caloric (along with affinities); and caloric was a hypothetical, imponderable substance, just like phlogiston. ${ }^{20}$

Moreover, there was also partial overlap of the methods used for studying phlogiston, caloric and other substances as well as their transformations. There is no empirical evidence for Chang's claim that the late "phlogistonists disregarded weight-based arguments because they were principlists" (Chang, 2012, p. 42). Lavoisier claimed that caloric could be measured with the calorimeter, based on the physical tradition to measure heat via its effects. Embedding caloric in an existing tradition of measuring temperature and other effects of heat (Chang, 2004), he unified this part of natural philosophy with chemistry. This was certainly an impressive achievement that may have spurred some chemists to accept the anti-phlogistic system. Yet the Swedish phlogistonist Bergman also involved phlogiston in quantitative reasoning, calculating its proportions by gravimetric analysis (see note 17). What is more, there was no chemical quantitative proof for the existence of caloric. As caloric was defined as an imponderable substance, it was ruled out a priori to evince it by the method of balancing the masses of educts and products of chemical reactions, for which Lavoisier became famous.

Phlogistonists were pioneers in the development of quantitative chemical methods, in particular the Swedish and German, based on their close links with mining and metal production. Not Lavoisier, but rather the phlogistonists had introduced quantitative chemical analysis and eudiometry (Boantza, 2013; Holmes, 1989, 1998, 2000; Levere, 2000). The German phlogistonist Klaproth even occasionally balanced the masses of the educts and products of chemical reactions. Clearly, many of Lavoisier's

\footnotetext{
19 Phlogistonists like Crawford and Kirwan offered slightly different explanations concerning this issue; see Boantza (2013), pp. 171-206.

20 This argument is evinced by statements of several historial actors (Boantza, 2013, pp. 209-211).
} 
analyses were more precise than those of the phlogistonists, as Lavoisier had precision instruments at hand that were not available for any other chemist. However, this fact was not due to a difference in methodology but rather in financial means. Unlike most chemists, the rich Fermier-Général of the old regime could afford expensive precision instruments (Holmes, 2000; Kusch, 2015), Furthermore, phlogistonists such as Klaproth had also long attempted to replace the traditional names of substances by systematic chemical names expressing composition, in a way similar to Lavoisier's (Klein, 2014).

Unlike Lavoisier, Klaproth had no access to Lavoisier's precision instruments. Nor did he transform the balance-sheet method into an argument for justifying new theories. The reason for the latter was not methodical difference per se. Whereas Lavoisier aimed to re-structure chemical theory, using the balance-sheet method in this distinct context, Klaproth devoted almost his entire scientific life to the complex quantitative analyses of hundreds of minerals. ${ }^{21}$ Generally speaking, I also argue that there was no methodological incommensurability between Lavoisier and the late eighteenthcentury phlogistonists (see Chang 2015). ${ }^{22}$

\subsection{Lavoisiers' ontology seen through the lens of studies of classification}

Concerning the bulk of substances constituting eighteenthcentury chemists' ontology of substances, the best insight in the character of Lavoisier's contribution to chemistry can be gained by comparing the phlogistonists' classificatory systems with the classification of chemical substances presented in the tableau de la nomenclature chimique, published by Lavoisier and his collaborators Louis Bernard Guyton de Morveau, Claude Louis Berthollet and Antoine Francois Fourçroy in 1787. The latter provides an overview of all substances at stake in Lavoisier's reforms. ${ }^{23}$

In his attempts to render his theory of scientific revolutions more precise, the late Thomas Kuhn proposed to compare trees of kinds and taxonomic systems for judgements about revolutionary change in science. ${ }^{24}$ Elsewhere we have studied in fine detail chemists' classification in the context of the phlogistic theories and Lavoisier's system (Klein \& Lefèvre, 2007; Lefèvre, 2012). We concluded that Lavoisier preserved much of the old taxonomies. Even if comparisons of taxonomies do not yield a crystal clear yardstick to identify all aspects of a scientific revolution, they enable us to get a better understanding of scientists' changes of ontologies.

The tableau de la nomenclature chimique preserved the old classes of metals, alkalis, earths, acids, salts, and alloys, which were the paradigmatic classes of substances in the conceptual system of compounds and affinity. In addition, it also integrated metal calces, now re-defined as metal oxides, as well as gases and a novel class of "simple substances." Thus it provided a more comprehensive classificatory system than any earlier classification of the phlogistonists.

\footnotetext{
21 Lavoisier's system did not extend to mineralogical chemistry (see note 2).

22 As has been pointed out above, it is beyond the scope of this particular paper to discuss this complex issue in detail.

${ }^{23}$ This classificatory table is contained in their Méthode de nomenclature chimique. (Guyton de Morveau, Lavoisier, et al., 1787). For bibliographical information about the latter see Klein and Lefèvre (2007), p. 87. For the relationship between classification and ontology of substances see Klein and Lefèvre (2007), 9, pp. 66-67.

24 Kuhn (1989, 1993, 2000), pp. 90-120. Kuhn's concepts of tree of terms and lexicon, and his no-overlap principle, have often been interpreted from a formal linguistic point of view (e.g., Garber, 2012). But they can also be related to scientists' practice of classification; see Buchwald (1992); Buchwald and Smith (1997); Klein and Lefèvre (2007), p. 67, p. 183.
}

The boldest move of the tableau was the introduction of a class of "simple substances." Lavoisier has often been praised as the chemist who introduced the modern concept of chemical elements in the sense of the most simple substances that cannot be further decomposed by chemical analysis. He defined "simple substances" in an operational way, highlighting the dependence of knowledge on the available analytical means of chemistry. Was this definition the result of a new attitude or a new ontology?

We have seen above that relativism concerning simpler and more compound substances existed long before Lavoisier. Eighteenth-century chemists had long been sceptical, or even agnostic, concerning the acquisition of experimental knowledge about the most simple elements. They had distinguished between simpler and more complex compounds, all of which belonged to the same flat ontology of substances. If Lavoisier changed anything in this respect, he was less relativistic and less sceptical than his predecessors. Whereas the majority of phlogistonists' postponed questions concerning ultimate elements or "principles," concentrating instead on the more proximate principles of natural substances, Lavoisier was more confident that contemporary chemical analysis yielded reliable results. Let us consider all substances that we could not further separate through chemical analysis, he proposed, to be "simple substances" rather than "simpler" ones. His concept of "simple substances" thus implied the proposal of a convention.

Lavoisier's "simple substances" were ordinary species of chemical substances, which had the same ontological status as chemical compounds. Hence, they were many by number, in distinction to the few causal elements, postulated by natural philosophies in the Artistotelian tradition. His class of 55 simple substances comprised the matter of light and caloric; the radicals of oxygen gas, hydrogen gas and nitrogen gas; "carbon," which was defined as the radical of charbon (charcoal); and additional 21 hypothetical radicals of various acids. It further included the 17 metals known at his time, considered to be relatively compounded compounds in the phlogistic taxonomy; and 5 earths and 3 alkalis, which the phlogistonists' had long considered to be relatively simple substances as well.

Lavoisier's hypothetical radicals of acids were constructed by analogy with the radicals of sulphuric acid and of phosphoric acids, which were common sulphur and phosphorus. His hypothetical radicals of muriatic acid (hydrochloric acid), carbonic acid, and of numerous vegetable acids had exactly the same ontological status as sulphur and phosphorus. They were defined as components of acids that had not yet been separated by chemical analysis. From an epistemological perspective, however, the vast majority of Lavoisier's radicals of acids differed from common sulphur and phosphorus due to their hypothetical nature.

Taken together, Lavoisier's new chemical system postulated altogether 27 hypothetical simple substances. Compared to the two hypothetical substances in the phlogistic system-phlogiston and matter of heat-this fact epitomizes the overall theoretical character of his chemistry. Contrary to common view, Lavoisier rendered chemistry not more empirical but more theoretical.

I have stated above that Lavoisier's concept of "simple substances" can be seen as a proposal of a convention. Inasmuch as this convention presupposed the flat chemical ontology of the phlogistonists it was not a novelty. What is more, like his predecessors, Lavoisier did not abolish wholesale the ancient concept of element, but rather sidestepped it. He still found it possible that future chemists might be able to isolate true "elements." The tableau even highlighted a particular group of simple substances-light, caloric, oxygen, and hydrogen - that were defined as candidates for simple elements. 


\subsection{A mirror image of the phlogistic taxonomy}

Now I come to an important taxonomic consequence of Lavoisier's introduction of a class of "simple substances." In Lavoisier's system many substances that the phlogistonists considered to be relatively compounded substances-namely, the 17 metals, sulphur and phosphorus-were re-defined as simple substances, while substances that the phlogistonists regarded to be relatively simple substances - the metal oxides (calces), sulphuric acid, and phosphoric acid-were defined as compounds. This reversal may be regarded to be revolutionary, since it concerned chemists' upper, or most basic, classificatory distinction between substances. The following arguments speak against this interpretation.

First, compared to the ontology of elements and mixts in the Aristotelian and Paracelsian tradition, Lavoisier's taxonomy implied the same flat ontology of chemical substances that we encounter in phlogistonists' affinity tables. It relied on the same conceptual system of chemical compounds and affinity and on the same type of paradigmatic substances, namely "chemical substances" in the narrow sense. Second, Lavoisier's reversal of classification on the upper classificatory level of distinction between simple and compound substances had no consequences concerning the majority of the particular classes of compounds. The class of permanent gases and of metal oxides (calces) excepted, all particular classes of chemical compounds presented in Lavoisier's tableau had long been constructed before (Klein \& Lefèvre, 2007, pp. 179-192). ${ }^{25}$ Furthermore, in both taxonomies the classes of salts and alloys were regarded to be chemical compounds, and the classes of alkalis an earths were (relatively) simple substances. Third, Lavoisier even preserved entire clusters of the phlogistonists' classes of substances. Hence, we have been able to present his anti-phlogistic classification as a "mirror image" of the phlogistic taxonomy. As a consequence the two alternative taxonomic systems could be easily transformed into each other through a single shift of two clusters of classes of substances (Klein \& Lefèvre, 2007, pp. 183-84).

Let us now turn to the boundaries of Lavoisier's tableau. What kinds of substances were excluded from it? Apart from organic acids, all plant and animal substances were excluded from the tableau (Klein \& Lefèvre, 2007, pp. 255-259). The tableau also excluded natural raw minerals such as ores and stones, which were at the epistemic focus of Swedish, German and even some French chemists. Furthermore, it excluded numerous useful materials that chemists studied well into the nineteenth century. Seen from the broader perspective of the eighteenth-century material culture of substances, Lavoisier's tableau was limited to the same cluster of paradigmatic chemical substances that the phlogistonists' had long discerned to be the most promising ones to establish rules, laws, and systematic classifications in chemical science. Together with the taxonomic features mentioned above, Lavoisier's limitation of his taxonomic system to "chemical substances" (as defined above) provides strong evidence for our argument of continuity.

\footnotetext{
25 Based on his classificatory principle according to chemical composition, Lavoisier added to the extant class of alloys a sub-class of several binary compounds of carbon, sulphur and phosphor (which had been known before). Hence, he modified the latter class, presented in the last column of the tableau. In a similar way, he extended the class of gases adding a sub-class of compounds of metal oxides with various substances. However, this did not change the main taxonomic structure of the phlogistic system, which consisted of two linked clusters of classes: one built around the understanding of neutral salts and the other one build around metals, their calces and their alloys.
}

\section{Types of causal explanations of chemical transformation}

If Lavoisier did not change chemists' ontology of substances, perhaps he introduced an ontological alternative with respect to chemical transformations. Did he alter chemists' causal explanation of chemical reaction or propose a novel type of chemical reaction? Eighteenth-century chemists explained chemical transformations in two very different ways. As we have seen above, all transformations represented in the affinity tables as well as combustion, calcination and the reduction of metal calces were explained as interactions or "re-actions" between different kinds of substances. According to this view, the substance components of the original substances separated and re-combined during the reaction process yielding new kinds of substances. This mechanical understanding of chemical transformations was supplemented by the concept of affinity. Any particular explanation of a distinct chemical reaction consisted of a narrative describing the ways in which the two proximate components of two interacting substances were moved in space, through affinity, and then combined in new ways. In a few cases chemists also assumed that a simple decomposition of a substance into its components was possible. For example, the red calx of mercury (mercury oxide) could be decomposed into mercury and dephlogistated air (oxygen gas). In such exceptional cases, fire was conceived to be the agent that separated the two components of a compound. Both the concept of simple analysis and of simultaneous decomposition and re-composition implied the same building-block model, which defined components as ordinary chemical substances or proximate principles. ${ }^{26}$

The second type of explaining chemical transformations was considerably older. It postulated that a substance species A can be transformed into a substance species B through a process of altering the qualities of $A$. This concept of transmutation of just one substance, which may be externally stimulated by another substance, was still widely accepted in the first half of the eighteenth century. Thus most early eighteenth-century chemists believed that base metals would ripen within the earth and thus be transformed into nobler metals, in analogy to the growing and ripening of plants on the surface of the earth. The same type of causal explanation was implied in the alchemical understanding of the transmutation of base metal into gold through chemical art. Chemists assumed that the qualities of iron, for example, were changed in the process of transmutation so that gold resulted at the end of the process. The ferment or philosophers' stone deemed to be necessary for performing this kind of transmutation was regarded as an external agent that merely promoted the transmutation of iron.

The theory of transmutation emerged in the context of medieval alchemy, not in the context of Aristotelian natural philosophy. The Aristotelian philosophy of elements, mixts, and generation could be easily linked with the alchemical theory of transmutation, notwithstanding the fact that the former had been elaborated with respect to a different explanandum, namely the existence of a broad variety of natural substances that possessed many different properties. Likewise, the early modern corpuscular philosophy could be easily linked with the alchemical concept of transmutation. Boyle's and Newton's corpuscular version of "transmutation" through alteration of properties of just one substance relied on the assumption that the distinct texture of the same kind of corpuscles

\footnotetext{
${ }^{26}$ This model should not be confused with corpuscular or atomic models. Chemists knew that large masses of solid substances did not react, but must first be pulverized or dissolved. Hence they assumed that the substances that underwent transformations were divided into small parts of substance. This empirical knowledge clearly differs from the theoretical concept of pre-existing atoms or corpuscles and the explanatory functions of the latter.
} 
caused the properties of a particular species of substances. Boyle and Newton theoretically endorsed transmutations, explaining them as internal re-shuffling of the texture of corpuscles. ${ }^{27}$

Like the late phlogistonists, Lavoisier extended the buildingblock model of chemical reactions along with the concept of affinity to all chemical transformations. He did not argue against the possibility of transmutation, but deliberately ignored it. Indeed, his theory did not provide any new explanatory concept that would have ruled out that transmutation was possible. Thus we come to a similar conclusion as in our comparison of Lavoisier's and the phlogistonists' ontology of substances. Lavoisier did not change chemists' ontology of types of chemical transformations. He neither introduced new concepts concerning chemical transformations nor enriched the world of existing types of transformations.

Let us now discuss briefly the question of why Lavoisier's reform was accepted. In their contributions to this symposium, Chang and Kusch have discussed this question in detail. I would like to add just one consideration in this respect. Germany's most famous chemist of the last third of the eighteenth century, Klaproth, was an empirically minded chemist who focussed his chemical studies on the chemical analysis of minerals (Klein, 2014). Like all chemists of his time, he was a phlogistonist, and he long hesitated to accept Lavoisier's antiphlogistic system. In 1792, the Royal Prussian Academy of Sciences asked him to evaluate Lavoisier's Traité de chimie. ${ }^{28}$ In his report, Klaproth conceded that phlogiston was a "hypothesis" and that the discovery of gases prompted many revisions of the phlogistic system. But he also stated that he was not able to decide between the two systems before he had access to precision instruments allowing him to repeat the alleged synthesis of water (Klaproth, 1792/93). As far as we know, Klaproth never performed the latter experiment. ${ }^{29}$ His own analytical program was independent of the two alternative systems. However, by 1807 at the very latest, Klaproth had accepted Lavoisier's system. He did so in a very specific context: his chemical teaching (Klaproth, 1807/ 08).

I have mentioned already that the late phlogistonists had developed many different versions of their theories. In the last third of the eighteenth century, each phlogistonist had his own individual theory concerning the nature of the different kinds of air, the relationship between phlogiston and the matter of heat, and some other items. This fact, I argue, was an obstacle to chemical teaching, given the fact that its audience consisted of non-professionals. The chemical systems built around phlogiston were split into many variations, which made it difficult to teach it in a representative and understandable way. By contrast, Lavoisier's system had the advantage that it was easy to teach, since it was consistent and since there was just one theoretical system.

I further argue that Lavoisier and his group had the advantage that they were the first chemists who elaborated a new chemical nomenclature, based on knowledge of composition, which had long been an ardent request in the chemical community. Their new nomenclature was based on their chemical theories along with their own system of classification (Klein \& Lefèvre, 2007, pp. 8795). It is very likely that resistance against Lavoisier's system would have been stronger, if the adherents of the phlogiston theory had proposed an alternative nomenclature, based on their own, alternative understanding of chemical composition. The latter, however, was an unlikely event, as the phlogistonists spoke with different tongues. Seen from the perspective of chemical teaching and

\footnotetext{
27 See Klein (1994) and the primary and secondary literature quoted there.

28 Archive of the Berlin-Brandenburg Academy of Science (ABBAW) I-IV-33, folio 147.

${ }^{29}$ See Dann's overview of his publications in Dann (1953), pp. 109-128.
}

communication, the acceptance of Lavoisier's system was a rational decision in the context of chemists' shared goals and communal interests.

\section{Conclusion}

In The Structure of Scientific Revolutions, Kuhn argues that "after discovering oxygen Lavoisier worked in a different world" (Kuhn, 1962, p. 117). By contrast, I have argued for a new understanding of Lavoisier's contribution to chemistry that puts stronger emphasis on continuity. Lavoisier worked in the context of the same flat ontology of chemical substances that had guided chemists for many decades. This ontology is epitomized in affinity tables. We can take Geoffroy's affinity table from 1718 as a historical marker that highlights those concepts and paradigmatic substances of eighteenth-century chemists that corresponded with Lavoisier's ontology. Lavoisier also reaped the rewards of a century of studies of chemical transformations, and he relied on the same type of causal explanation of chemical transformations that is displayed in affinity tables. These tables were constructed by phlogistonists, and they also implemented phlogiston. There is no incommensurability between Lavoisier's system and the late phlogistonists' ontology of substances and ways of causal explanation of chemical transformations. Nor is there any methodological incommensurability.

In their research, the vast majority of late eighteenth-century phlogistonists' had adopted a pragmatic approach, focussing on questions that they could tackle with the available tools. With exception of teaching, they put aside fundamental theoretical problems concerning simple elements (principles and atoms), the internal constitution of "mixts," the relationship between matter of heat and phlogiston and so on. Lavoisier brought such theoretical issues back on stage along with more specific theoretical questions concerning the understanding of combustion, permanent gases, acidity and so on. Thus he took up theoretical challenges that the phlogistonists tried to avoid. The overall theoretical character of his chemistry is highlighted by the fact that his new taxonomic system postulated altogether 27 hypothetical simple substances. Lavoisier rendered chemistry not more empirical but more theoretical.

Elaborating and justifying his hypotheses, Lavoisier systematically used precision measurement and quantitative chemical analysis, which the phlogistonists had introduced into chemistry. His balance-sheet method was not a novelty but just an extension of the principle of mass conservation that was presupposed in quantitative chemical analysis. Thus his distinct contribution concerning quantitative methods was refinement and implementation into theoretical research and justification.

The components of Lavoisier's theoretical system were mutually well adapted. But the fact that he proposed a coherent theoretical system, which covered several chemical sub-fields, must not equated with the argument that he initiated a revolution of chemistry. Scientific "revolutions," Kuhn observed, resemble political revolutions, as they are upheavals on a deep level that change scientists' mode of community life (Kuhn, 1962, p. 94). Instead of talk about small scientific revolutions or "minirevolutions" (Kuhn, 1962, pp. 7-8, 66, 92, 116; Barker, Andersen, \& Chen, 2006, p. 67), it may be more appropriate to use terms like reform with respect to less radical changes such as Lavoisier's. Lavoisier's contribution to chemistry is impressive, but it was limited to the most ordered subfields of chemistry that the chemists before him had well prepared.

\section{Acknowledgements}

I thank Alan Chalmers, Wolfgang Lefèvre, Trevor Levere, and Lucia Lewowicz for helpful comments. 


\section{References}

Barker, P., Andersen, H., \& Chen, X. (2006). The cognitive structure of scientific revolutions. Cambridge: Cambridge University Press.

Bergman, T. (1785). A Dissertation on elective attractions [= De attractionibus electivis disquisition 1775], (T. Beddoes. London: J. Murray., Trans.).

Bloor, D. (1976). Knowledge and social imagery. London: Routledge \& Kegan Paul.

Boantza, V. D. (2013). Matter and method in the long chemical revolution. Burlington: Ashgate.

Buchwald, J. Z. (1992). Kinds and the wave theory of light. Studies in History and Philosophy of Science, 23(1), 39-74.

Buchwald, J. Z., \& Smith, G. E. (1997). Thomas S. Kuhn, 1922-1996. Philosophy of Science, 64, 361-376.

Chalmers, A. (2012a). Klein on the origin of the concept of chemical compound. Foundations of Chemistry, 14, 37-53.

Chalmers, A. (2012b). Intermediate causes and explanations: The key to understanding the scientific revolution. Studies in History and Philosophy of Science, 43(4), 551-562.

Chalmers, A. (2013). Review of $\mathrm{H}$. Chang, is water $\mathrm{H}_{2} \mathrm{O}$ ? Science E' Education, 22(4), 913-920.

Chang, H. (2004). Inventing temperature: Measuring and scientific progress. Oxford: Oxford University Press.

Chang, H. (2012). Is water $\mathrm{H}_{2} \mathrm{O}$ ? Evidence, realism and pluralism. Heidelberg, New York, London: Springer.

Chang, H. (2015). The Chemical Revolution revisited. Studies in History and Philosophy of Science, 49, 91-98.

Crosland, M. (2000). "Slippery Substances": Some Practical and conceptual problems in the understanding of gases in the pre-Lavoisier Era. In F. L. Holmes, \& T. H. Levere (Eds.), Instruments and Experimentation in the History of Chemistry (pp. 79-104). Cambridge, Mass: MIT Press.

Dann, E. (1953). Martin Heinrich Klaproth (1743-1817): Ein deutscher Apotheker und Chemiker, sein Weg und seine Leistung. Berlin: Akademie Verlag.

Duncan, A. (1996). Laws and order in eighteenth-century chemistry. Oxford: Clarendon Press.

Garber, D. (2012). Incommensurabilities. Historical Studies in the Natural Sciences, 42, 504-509.

Geoffroy, E.-F. (1718). Table des differents rapports observés en Chimie entre differentes substances. Histoire de l'Académie Royale des Sciences: avec les mémoires de mathématique et de physique pour la même année, 202-212.

Guyton de Morveau, L. B., Lavoisier, A. L., Berthollet, C. L., \& Fourcroy, A.-F. (1787). Méthode de nomenclature chimique. On y a joint un nouveau systême de caractères chimiques, adaptés à cette nomenclature, par MM. Hassenfratz et Adet. Paris: Cuchet.

Holmes, F. L. (1989). Eighteenth-century chemistry as an investigative enterprise. Berkeley: University of California Press.

Holmes, F. L. (1998). Antoine lavoisier - The next Crucial Year or the Sources of his quantitative method in chemistry. Princeton: Princeton University Press.

Holmes, F. L. (2000). The evolution of Lavoisier's chemical apparatus. In F. L. Holmes, \& T. H. Levere (Eds.), Instruments and Experimentation in the History of Chemistry (pp. 137-152). Cambridge, Mass: MIT Press.

Kim, M. G. (2003). Affinity, that Elusive Dream: A Genealogy of the chemical revolution. Cambridge, Mass: The MIT Press.

Klaproth, M. H. (1789-1993). Vorlesungen über Experimental-Chemie. In R. Stolz, P. Lange, \& R. Schwertner (Eds.). Berlin: Verlag für Wissenschafts- und Regionalgeschichte M. Engel.

Klaproth, M. H. (1792/93). Rapport de M. Klaproth touchand l'ouvrage intitutlé: Traité élementaire de Chimie etc. par Lavoisier T. 1 \& 2, Paris 1789. Mémoires de l'Académie Royle des Sciences et Belles Lettres, 16-19.
Klaproth, M. H. (1807/08). Ed. (from a manuscript by S. F. Barez) by B. Engel. In Chemie. Berlin: Verlag für Wissenschafts- und Regionalgeschichte M. Engel, 1994.

Klein, U. (1994). Verbindung und Affinität, die Grundlegung der Neuzeitlichen Chemie an der Wende des 17. zum 18. Jahrhundert. Basel: Birkhäuser.

Klein, U. (1995). E. F. Geoffroy's table of different 'Rapports' observed between different chemical Substances-A Reinterpretation. Ambix, 42(2), 79-100.

Klein, U. (2012). Objects of inquiry in classical chemistry: Material substances. Foundations of Chemistry, 14, 7-23.

Klein, U. (2013). Materiality and abstraction in modern chemistry. In J. P. Llored (Ed.), The philosophy of Chemistry: Practices, Methodologies, and concepts (pp. 342-363). Newcastle: Cambridge Scholars Publishing.

Klein, U. (2014). Klaproth's discovery of Uranium. In U. Klein, \& C. Reinhardt (Eds.) Objects of chemical inquiry (pp. 21-46). Sagamore Beach: Watson.

Klein, U., \& Lefèvre, W. (2007). Materials in eighteenth-century science. Cambridge, Mass: MIT Press.

Kopp, H. F. M. (1966). Geschichte der Chemie (Vol. 4). Hildesheim: Olms.

Kuhn, T. S. (1962). The structure of scientific revolutions (2nd. Ed.). Chicago and London: University of Chicago Press, 1970.

Kuhn, T. S. (1989). Possible worlds in history of science. In S. Allén (Ed.), Possible worlds in Humanities, arts, and Sciences: Proceedings of Nobel symposium 65 Berlin: de Gruyter. pp. 9-32, 49-51.

Kuhn, T. S. (1993). Afterwords. In P. Horwich (Ed.), World changes: Thomas Kuhn and the nature of science (pp. 311-341). Cambridge, Mass: MIT.

Kuhn, T. S. (2000). The road science structure, philosophical essays, 1970-1993, with an autobiographical interview. Chicago: The University of Chicago Press.

Kusch, M. (2015). Scientific pluralism and the Chemical Revolution. Studies in History and Philosophy of Science, 49, 69-79.

Lavoisier, A. L. (1789). Traité élémentaire de chimie: Présenté dans un ordre nouveau et d'après les découvertes modernes (Vol. 2). Paris: Cuchet.

Lefèvre, W. (2012). Viewing chemistry through its ways of classification. Foundations of Chemistry, 14, 25-36.

Levere, T. H. (2000). Measuring gases and measuring goodness. In F. L. Holmes, \& T. H. Levere (Eds.), Instruments and Experimentation in the History of Chemistry (pp. 105-135). Cambridge, Mass: MIT Press.

Lewowicz, L. (2011). Phlogiston, Lavoisier and the purloined referent. Studies in History and Philosophy of Science, 42, 436-444.

Löw, R. (1977). Pflanzenchemie zwischen Lavoisier und Liebig (Vol. 1). Straubing: Donau-Verlag. Münchner Hochschulschriften: Reihe Naturwissenschaften.

Macquer, P. J. (1766). Dictionnaire de chymie, contenant la théorie et la pratique de cette science, son application à la physique, à l'histoire naturelle, à la médicine et à l'economie animale (Vol. 2). Paris: Lacombe.

Partington, J. R. (1961-1970). A history of chemistry (Vol. 4). . London: Macmillan.

Porter T. M. (2009). How science became technical. Isis, 100, 292-309.

Siegfried, R. (1982). Lavoisier's table of simple substances. Ambix, 29(1), 29-48.

Siegfried, R. (2002). From elements to atoms. A history of chemical composition. Philadelphia: American Philosophical Society.

Siegfried, R., \& Dobbs, B. J. (1968). Composition, a neglected aspect of the chemical revolution. Annals of Science, 24(4), 275-293.

Stahl, G. E. (1730). Philosophical principles of universal chemistry: Or, the foundation of a scientifical manner of inquiry into preparing the natural and artificial bodies for the uses of life (Peter Shaw, Trans by). London: Osborne and Longman

Stroup, A. (1990). A company of scientists: Botany, patronage, and community at the seventeenth-century parisian royal academy of science. Berkeley: University of California Press.

Tomic, S. (2010). Aux Origines de la Chimie Organique: Méthodes et Pratiques des Pharmaciens et des Chimistes (1785-1835). Rennes: Presses Universitaires de Rennes. 